Eduardo Solar Correa

\title{
La reforma del programa de castellano
}

LOS DEFECTOS DEL PROGRAMA ACTUAL

ESDE hace tiempo se viene hablando, entre los profesores de castellano. de la necesidad de una reforma en el programa de esa asignatura y, según entendemos, ella se halla ya en estudio y en muy buenas manos.

El problema, mirado en conjunto, no es, a nuestro juicio, tan complejo como podría suponerse. ni sería justo abominar del programa actual, estudiado y redactado por personas muy idóneas.

Los reparos más serios que suelen hacérsele-y que varios años de práctica han puesto en relieve-se reducen tal vez a dos:

1. Exagerado número de malerias; y

2. Dificultad que ofrece la enseñanza de la literatura arcaica.

\section{NECESIDAD DE REDUCIR LAS MATERIAS}

El primer punto. para cualquiera que haya profesado una cátedra de castellano-me refiero especialmente a los años cuarto. quinto y sexto-tiene el carácter de una verdad matutina. Es imposible pasar en un año escolar la enorme lista de asuntos comprendidos en los programas de dichos cursos. pasarla-se 
entiende-en una forma medianamente provechosa. Sólo puede hacerse un estudio superficial en que la memoria ocupa el principal papel. Un profesor que pretendiese explicar a fondo algunos puntos y hacer razonar sobre ellos a sus alumnos, o que quisiese ejercilar a éstos-detenidamente-en la redacción. se encontraria con que el año habia expirado y la mitad del programa aun no habia sido visto.

En el plan de sexto año. existe una nota que dice: .Dada la insuficiencia del liempo destinado a esta enseñanza, podrá el profesor tratar uno solo o dos. según los casos, de los autores designados en cada una de las letras de esle programa..

Indica esta frase que los propios autores del programa comprendieron-por lo menos tratándose del sexto año-que aquel extenso número de materias era inabarcable en un año escolar. Cabria preguntarse ¿por qué no redujeron entonces las mateterias? ¿por qué dictaron un programa que ellos mismos estimaban irrealizable en la práctica? Hecho. en realidad. sorprendente: pero hay algo peor. $y$ es que en los exámenes suele exigirse todo. absolulamente todo el programa, y aún a veces más. De manera que el defecto que creyó evitarse con la paradójica nola no se eviló. y aun se ve agravado en muchos casos.

Circunstancia es ésta que prueba que el mal se halla, no sólo en los programas. sino también en el criterio de los maes. tros. La mejor de las leyes como el mejor de los planes universitarios fracasará siempre, mientras los encargados de aplicar unas y otros no interpreten debidamente su letra y su espiritu.

Pero de los dos problemas, éste es el más sencillo. Bastará concrelar aquellas largas listas de autores a las figuras más culminantes y significativas de cada época, cxigiéndose que se les estudie profundamente. no tanto en los detalles biográficos y bibliográficos-no siempre interesantes y trascendentes. - sino en su espiritu y en su obra, mirada ésta como expresión humana. como arquetipo de una escucla o tendencia estética y como símbolo de una época, ya sea-según los casos-en el triple aspecto politico, intelectual y social, ya en uno solo de ellos. 
El libro de tiempos pretéritos, lejos de aparecérsele como fria momia. cobraria vida e interés a los ojos del estudiante: y ésle aprendería a leer con amor las obras maestras del idioma. exprimiendo de ellas su jugo vilal: y luego. fruto natural de esa lectura apasionada. vendria el conocimiento de la lengua y el gusto por el buen decir. que en último análisis. debe ser la verdadera finalidad de la asignatura a que nos referimos.

Más adelante tendremos ocasión de insistir sobre la conveniencia de mirar el problema desde los puntos de vista indicados; pero ya que hemos insinuado aqui la necesidad primordial de que el niño salga de las aulas redaclando convenientemente. nos atreveríamos a proponer-como un medio de contribuir a ese ideal-que se asigne en los exámenes mayor importancia a los cuadernos de composiciones hechos en el año. Si se llegara a que la nota media de éstos constituyese la milad de la prucba. o sea, que la nola de los cuadernos se sumase a la del examen oral y ambas, divididas por dos, produjesen la nota definitiva, se daria. sin duda, un gran paso en el sentido de fomentar la buena redacción de los jóvenes, hoy dia detestable en la mayoria de los casos.

No ignoramos que el nuevo mélodo de exámenes consulta una prueba escrita, pero ella no contribuirá gran cosa a mejorar ese termómetro de la cultura del individuo que es el lenguaje y el estilo. Tal resultado no podrá alcanzarse sino mediante una labor paciente y metódica, una labor de todo el año en que de consuno cooperen el maestro y el alumno. Es preciso corregir la natural inexperiencia del nin̄o, pero aủn más la tendencia de nuestra raza a la improvisación. a hacer las cosas de cualquier manera, sin amor, y esto jamás podrá conseguirlo la precipilada prueba escrila, de fines de año.

Ante todo debe considerarse, sin embargo, la reducción del programa. Ese es el quid de la cuestión. Cambiar los rumbos en uno u otro sentido sería inútil si en las clases de castellano se hubiese de continuar el vertiginoso desfile de nombres de autores y de obras a que obliga el actual plan universitario. 


\section{PROYECTO DE INVERTIR EL ORDEN DE LAS MATERIAS}

El otro punto-el de la dificultad que ofrece la enseñanza de la literatura arcaica-es quizás más debatido, pero no menos soluble.

Cúlpase, en general. de esta dificultad al hecho de encontrarse su estudio situado en el cuarto año de humanidades. época en que-según se dice-los estudiantes no están aún en situación de apreciar y gustar las primitivas manifestaciones de nuestra lengua.

Buscando una solución a tal inconveniente, se ha propuesto la traslación del estudio de la literatura preclásica al sexto año y el de la literatura moderna al cuarto. o sea, invertir el orden natural de las materias.

Si hemos de hablar con franqueza, no titubearemos en afirmar que el remedio resultaria mucho peor que la enfermedad. El defeclo o inconveniente que se procura salvar está hoy localizado en el cuarto año y con el cambio que se intenta no se conseguiria sino hacer defectuoso todo el programa. lo que significaría un mayor mal.

En términos generales, el nuevo programa distribuiria las materias asi:

Cuarfo año: Literatura española moderna (siglos XVIII. XIX y XX).

Quinto año: Literatura española clásica (siglos XVI y XVII.) Sexto año: Literalura española preclásica (siglos XII. XIII. XIV y XV).

Primera dificultad que este sistema acarrearía. Dentro de cada año ¿en qué orden se estudiarian las malerias? En el IV ¿se comenzaria con el siglo XVIII. se seguiría con el XIX y después con el XX? Si asi se hiciera tendriamos que la época más incolora y menos española de las letras peninsulares serviría de introducción al estudio de ellas: lo que parece absurdo. Tendriamos, además, que el alumno de cuarto, que al terminar el año estaba viviendo-lilerariamente-en pleno siglo XX. debería 
saltar de súbito al siglo XVI. con que se iniciaria el estudio de quinto año. y al finalizar éste, al siglo XII, con que se iniciaria el estudio de sexto. Verdaderos saltos mortales capaces de hacer perder el sentido a personas mucho más reflexivas y conscientes que los estudiantes chilenos de humanidades. a menudo inaptos para el más elemental raciocinio. mentes faltas de orden lógico, incapaces con frecuencia de hilvanar una frase congruente y completa. $\mathrm{iAh}$, el rompe-cabezas de los profesores de castellanol Enseñar a pensar y a expresarse en forma ordenada y clara. $Y$ que no lo consiguen en la mayor parte de los casos ha podido corroborarlo cualquiera que haya asistido a esas asambleas estudiantiles - de estudiantes universitariosverdaderas palestras de incongruencias ideológicas y desorden sintáxico. Verlos hablar deja en el ánimo la más penosa impresión. Es una lucha trágica entre la voluntad que quiere y la inteligencia que no puede. Cada cerebro remeda un pequeño caos que se revuelve en si mismo sin que nunca suene la hora del fiat lux salvador, y el incipiente tribuno recobra su asiento sin que nadie quede enterado de lo que dijo o de lo que quiso decir.... aparle de algunas frases hechas. tan sonoras como huecas y vulgares. que tienen la virtud de mostrarnos otra zona baldía de esos mismos cerebros: la falta de educación estéfica.

Volviendo a nuestro programa de castellano. supongamos que sus reformadores-consecuentes con la indole de la reformaeviten en el aprendizaje de la literatura los sallos mortales de que hablábamos, y exijan un estudio ordenado y metódico. pero de adelante para atrás. Es decir, se comenzaria en cuarto año estudiando el siglo XX hasta terminar en el sexto con el siglo XII.

¿Qué ventajas aportaria este sistema?

La única que se hace valer es que la literatura arcaica, en vez de estar situada en el cuarto año. como ahora, quedaria en el sexto, cuyos estudiantes, con dos años más. con mayor cultura y preparación. estarian en situación de interesarse por esa literatura que no interesa a los de cuarto.

Supongamos que asi ocurra y procuremos sopesar este hipo- 
tético provecho con los inconvenientes que de la misma reforma se derivarian.

Para poder apreciar con justeza las ventajas o desventajas de una reforma como esta, es indispensable elevarse por sobre el detalle y mirar las cosas en conjunto. Hay que examinar si la reforma es útil para la cullura literaria general del niño-que es lo que importa-o si sólo se beneficia una sección de ese estudio. perjudicándose el conjunto.

No tememos engañarnos al sostener que, en el mejor de los casos, ocurriria lo último. Concedamos que los jóvenes de sexto año-por la circunstancia de pertenecer a dicho curso-llegaran a interesarse por los monumentos primilivos del idioma y adquirieran nociones conscientes de filología y gramática histórica.

Pero ¿cuál es el objeto de la enseñanza decastellano? ¿Formar eruditos en ciernes y aprendices de filólogos o proporcionar una cultura lileraria amplia que. capacilando a los jóvenes para expresarse con claridad y corrección. les procure una idea general del origen y desarrollo de nuestra literatura y nuestra lengua?

Pensamos que lo postrero. y en este caso la reforma no podria menos de ser funesta. Sería agravar el mal de que adolece fodo nuestro sistema universitario, señalado y esfudiado con gran acierlo por el señor Rector de la Universidad de Chile, don Claudio Matte, en unos substanciosos reportajes que no ha mucho vieron la luz en El Mercurio de Santiago. esto es, seria ahondar en el mal de los especialistas que, enamorados de su especialidad, olvidan el objeto y el interés general de la enseñanza.

El sistema de aprender una literatura en forma regresivasea por medio de saltos o siguiendo un estricto orden crono'lógico a la inversa-es de todo punto inaceptable: es un sistema, a nuestro juicio. fundamentalmente erróneo, cuyo único mérito seria el de su originalidad, pues no sabemos que en parte alguna del mundo se haya ideado nada semejante.

El desarrollo de una literatura es esencialmente evolutivo: todo en ella está ligado, concatenado: sus diversos fenómenos 


\section{La reforma del programa de castellano}

tienen a menudo entre sí la relación de causa a efecto: entre una época y otra época, entre una obra y otra existe con frecuencia tan intima trabazón que no es fácil comprender una sin conocer la que la há precedido y muchas veces engendrado. ya sea por estimulo directo, ya como reacción.

Imposible, por ejemplo, penetrar el por qué de la edad de oro de la literatura caslellana si no se han estudiado los siglos anteriores, sobre todo el siglo XV en que se preparó y realizó la unidad politica española y se introdujo en la península la simiente del Renacimiento Haliano; quien no conozca previamente el periodo neo-clásico del siglo XVIII. jamás llegará a comprender el significado del Romanticismo del siglo XIX. y quien no conozca éste no se explicará el Realismo que le siguió: incomprensible será siempre la aparición .El Quijote, para quien nada sepa de sLa Celestina, ni del «Amadis», y .El Lazarillo. para quien ignore ‘El Libro de Buen Amors y la obra del bachiller don Fernando de Rojas; para apreciar el teatro clásico español y la magna figura de Lope. es indispensable saber de la tragicómica historia de Calixto y Melibea, de los balbuceos dramálicos de Encina y Lope de Rueda, del viejo antagonismo entre poetas eruditos y populares. elc., etc.

En una literatura nada surge por generación espontánea. Todo liene sus causas y antecedentes. Ningún fenómeno literariosalvo excepción rarisima-puede ser explicado aisladamente y en si mismo*.

Tal afirmación tiene el carácter de una verdad incontrovertible y de ella fluye la necesidad absoluta del orden sucesivo y cronológico en el esludio de la hisloria literaria.

Dislocar las malerias, estudiar épocas y obras sin conocer las que les han precedido constituiria un defecto vital: se estudiaría mal toda la literatura - no solamente la arcaica - y se fomenfaría en el espíritu de los alumnos la falta de orden, de método.

- Podria objetarse que para comprender una liferafura es muchas veces necesario estudiar ofras extranjeras que han influido en ella y que, sin embargo. no se hace asi. No hay duda, pero este defeclo o vacio inevitable en ningún caso autorizaria para incurrir en ofro mayor y perfectamente evitable. 
nativa en ellos; y el profesor carecería del acicate de la inteligencia que es el abligar a los estudiantes a rastrear, a descubrir por si mismos, el origen y las causas de cada fenómeno literario.

\section{LA ENSEÑANZA DE LA LITERATURA ARCAICA}

¿Qué se diria de un arquitecto que imaginase construir primeramente el segundo piso de un palacio, y después el primero. y por último los cimientos?

Aceptemos. sin embargo, que al arquitecto de almas que es el maestro le sea permitido emplear semejante orden constructivo y que, tratándose del idioma patrio. llegue a enseñar la literatura moderna antes que la clásica y ésta antes que la arcaica.

Pero ¿se conseguiria el resultado apetecido? ¿Los alumnos de sexto año se encontrarian, realmente, en situación de gustar las lelras preclásicas y de interesarse por los problemas filológicos que les son inherentes?

Arduo problema. Al iniciar el estudio de los monumentos arcaicos habrian ya estado en comercio espiritual con los modernos aulores españoles, habrian sentido en sus páginas vibrar la sensibilidad de su siglo; sus jóvenes inteligencias. despertadas al calor de las ideas nuevas, hallarianse moldeadas en ellas, y su guslo estaría, por decirlo asi, aclimatado al estilo más liviano. sutil y sugerente de las obras de nuestros dias.

En tales circustancias, ¿seria lácil retrotraer su mente a las primeras manifestaciones literarias de la lengua, hacerlos interesarse por aquellos poemas ingenuos $y$. muchas veces, de indigesla lectura? ¿El arle limitado y rudo de estos escritores y su culfura primitiva y sencilla no es probable que estén mucho más en consonancia con cerebros infantiles que aun no conocen los refinamientos del arle moderno, que aun no han vibrado con la moderna sensibilidad?

Una buena reforma de nuestro programa actual podria sintetizarse en cuatro palabras: suprimir datos y ahondar ideas. 
La reforma del programa de casfellano

En la literatura arcaica convendria, no la traslación de la materia a otro año, sino dejarla donde está, que es su pueslo natural y obligado, pero hacerla más agradable y accesible a los alumnos.

¿En qué forma? Sería suficiente, para ello. simplificar el programa, dejándolo reducido a un mínimum indispensable, ahondar en la significación espiritual de los monumentos primitivos antes que en su letra, relacionar estas obras con la vida y costumbres de su tiempo. estudiar debidamente-lo que hoy no se hace-las diversas regiones de España con sus caracteristicas geográficas y psicológicas, cuya diferenciación lendrá más tarde lanta importancia en los diversos caracteres de la literatura española: en suma, insuflar la vida - y con ello interés-en lo que hoy es erudición monólona y fría.

\section{LA LECTURA DE LOS TEXTOS ARCAICOS}

No pequeña importancia para conseguir este resultado tendrá el que se provea a los estudiantes de textos de lectura que se hallen a su alcance. Los que actualmente se emplean están. sin duda, hechos con gran conocimiento de las letras arcaicas. pero no son pedagógicos. Los trozos de estas antologias se han tomado con cientifica escrupulosidad de las ediciones más exactas y perfectas que la erudición haya publicado. Para el estudio del Poema del Mio Cid. por ejemplo, se insertan trozos de la magistral edición anotada de Menéndez Pidal, verdadera golosina para eruditos y filólogos, pero incomprensible e ilegible para estudiantes de humanidades y aun para muchos bachilleres. La lectura del castellano arcaico ofrece a personas no avezadas casi tanta dificultad como ofreceria la lectura del italiano o el portugués a quienes ignoran dichas lenguas.

Léase cualquier trozo tomado al azar del Poema del Cid (edición de Menéndez Pidal):

Todos essa noch foron á sus posadas. mio Çid el Campeador al alcaçer entrava: reçibiólo doña Ximena e sus fijas amas: 
- ¿ ¿Venides, Campeador, buena cinxiestes espada!

- Muchos díns vos veamos con los ojos de las caras!.

-.Grado al Criador, vengo, muger ondrada!

- Yernos vos adugo de que avremos ondrança:

-Gradimelo, mis fijas, ca bien vos he casadas!.

(Canlar segundo)

Nos deliene por nada el que en buena ora naçió calças de buen paño en sus camas mefió. sobrellos unos çapalos que a grant huebra son. Vistió camisa de rançal tan blanca commo el sol, con oro e con plata todas las presas son, al puño bien están, ca él se lo mandó: sobrella un brial primo de çiclatón. obrado es con oro, pareçen por o son. Sobreslo una picl vermeja, elc.

(Cantar tercero)

Hemos transcrilo dos trozos cualesquiera, no de los más difíciles. Empero, estamos ciertos de que un hombre de los que suelen llamarse ilustrados entre nosotros, un profesional por ejemplo.-no ya un alumno de cuarlo o de sexlo año-soportaría con trabajo la lectura de cinco o diez páginas similares y al lerminar-si fuese sincero-nos diría que había entendido poco y que se habia interesado menos.

Obsérvese, por otra parte, que los lextos que se ofrecen a los jóvenes estudiantes, en su severidad erudita, conservan la inestable ortografia primitiva: alli se puede leer averes. dezir, conpaña, enbiar, cavallo, avrá, onor, ospedar, suzio, bivo, elc., elc.

Todo eslo tiene dos inconvenientes serios: es el primero que se hace a los niños más engorrosa la lectura de los preclásicos. y el segundo. que se contribuye a perturbar su ortografia, a menudo insegura y defectuosa, aun después de abandonar las aulas secundarias. Los examinadores de bachillerato no nos dejarán mentir: háblese con cualquiera de ellos y se le oirá decir. desalentado. que el ochenta por ciento de sus examinandos, en las pruebas escritas, no sólo redactan mal, en forma a veces ininteligible. sino que aun incurren en numerosas y graves fallas ortográficas. 
La reforma del programa de castellano

Mucho, sin duda, se remediaria, en uno y otro sentido-es decir en la dificullad de leer los textos primitivos y en el perjuicio que dicha lectura ocasiona a la ortografia infantil-si se acordara proporcionar a los alumnos versiones, no eruditas. sino modernizadas, pero que conservasen su sabor arcaico. Existen algunas excelenles, v. gr. la versión del Poema de Mio Cia de Pedro Salinas. No obstante. para que el alumno pueda conocer siquiera de visus la forma original en que aquellas obras fueron escritas y apreciar-con la ayuda del profesor-las transformaciones y deformaciones del idioma, sus allernativas y vicisitudes, convendría que en los textos el estudiante encontrase vis a vis ambas versiones: la original y la traducida a lenguaje moderno.

$\mathrm{Y}$ asi los alumnos de cuarto año podrian llegar hasta deleilarse con la lectura de las obras preclásicas. La psicologia infantil -es útil recordarlo-liene mucho de la psicología primitiva, y quizás siguiesen el relato de las proezas e infortunios del Campeador de Vivar con un interés pariente del éxtasis con que nuestros lejanos abuelos los escucharon en plazas, campamentos y castillos dé labios de un pobre y vagabundo juglar.

Pero si ni siquiera entienden lo que leen. ¿cómo pucde soñarse en interesarlos?

Una lectura de la indole que sugerimos no proporcionará a los jóvenes un conocimiento cientifico o erudito de los libros arcaicos: pero, en cambio. se habrá logrado que los conozcanque conozcan su espiritu y sentido. que es lo más importanle -y que no cobren aversión a su estudio. $Y$ entonces podrá esperarse que, más tarde, con la capacidad suficiente. afraidos por el grato recuerdo de los viejos versos leidos en los bancos escolares, vuelvan a ellos emocionados y anhelen paladearlos en sus fuentes primeras.

\section{IMPORTANCIA SECUNDARIA DE LA GRAMATICA}

En el proyecto de trasladar el estudio de la literatura preclásica al sexto año. se enfoca principalmente el interés gramatical y filológico. 
A nuestro parecer. es una verdadera ilusión, lal vez un trabajo perdido, pretender introducir a los jóvenes en los secretos de la filologia sin previo conocimiento del latín : Todo estudio filológico del castellano, por elemental que sea, sin la base latina es simplemente un castillo de naipes, un puro ejercicio nemotécnico sin ventaja alguna.

No es posible olvidar, por otra parte, que dicho estudio sólo tiene una importancia secundaria dentro del plan general del ramo a que nos referimos, y no sería dable perjudicar el conjunto en atención a él. De los estudiantes de humanidades tres - cuatro entre mil puede que se interesen por la ciencia filológica-ciencia de especialistas-y aun a estos pocos les serán de escaso servicio los rudimentos aprendidos en las aulas secundarias, debido a su inconsistencia, a su falta de base.

Lo esencial es que el alumno aprenda a amar la lectura, a hablar y escribir de modo satisfactorio. a discernir entre una obra de mérito y otra sin valor, y en fin, a formarse un concepto preciso, aunque sintético. del espiritu y desarrollo de la lengua y literatura españolas en relación con la vida politica. intelectual y social de la peninsula.

Y nada de todo eslo enseña la ciencia de Bello y de Hanssen. Allá por el siglo $\mathrm{V}$ anles de Cristo, en la Grecia de Pericles. nadic conocia la gramática ni de nombre * y floreció. sin embargo, la más brillante constelación de pensadores, escritores y artistas de que pueda enorgullecerse la Humanidad.

La gramática y la filología son ciencias auxiliares que deben conocer a fondo los eruditos en disciplinas lingüisticas y literarias. y los maestros del ramo, pero no hay para qué atiborrar con ellas las mentes infantiles, inaptas para este género de estudios.

- ICuántas ventajas de orden culfural, psicológico, filológico, literario y esféfico fraería la implantación del latin! La idea, Felizmente, comienza a abrirse paso, pero será preciso esperar todavia mucho tiempo.

* Dionisio de Tracia, nacido en Alejandria, una centuria antes de Cristo, es aufor, según se dice, de la primera gramática griega. Escribióla, no para enseñor el griego en Grecia-lo que enfonces hobría parecido extravagantesino para enseñarlo en Roma, donde prolesó una cátedra de bellas artes en fiempos de Pompeyo. 
Bien mirado el asunto, dichas ciencias, dentro de la asignatura de castellano, ocupan un rol semejante al que en la asignatura de historia tendrían la Paleontología. la Numismática. la Epigrafia y tantas otras disciplinas auxiliares de que el historiador se sirve en sus investigaciones. ¿Sería aceptable que, en vez de aprovechar los breves años escolares en dar a conocer a los jóvenes el desenvolvimiento de la Humanidad, los grandes hechos pasados con sus causas y consecuencias. el espíritu y cultura de los pueblos influyentes y señeros en los destinos del mundo, se entregase el profesor de historia a la árida tarea de instruir a sus alumnos en la ciéncia de los fósiles, o a determinar el valor histórico de monedas y medallas antiguas, o a desentrañar el misterio de abstrusas inscripciones cuneiformes?

El aprendizaje de la gramática en la escuela secundaria. más que una necesidad, es una tradición-una tradición de veintitantos siglos-y no es posible eliminarlo; pero conviene reducirlo a ciertas ideas generales sobre las categorias gramaticales y las transformaciones y deformaciones de la lengua.

En todo caso, no es posible aceptar que. en obsequio a él. se inlenle alterar el orden natural de las materias. ni más ni menos que si se tratase de un juego en que barajando las cartas pudiese esperarse un mejor resultado.

\section{UNA ULTIMA PALABRA}

Hay cierta tendencia a confundir la enseñanza que corresponde a los estudiantes de humanidades-fuluros abogados, médicos, agricultores, comerciantes, efc.-con la instrucción que conviene a los maestros. Nuestros estudios secundarios-podría decirsenos-no son en general sino una reducción o sintesis de los que se hacen en las aulas superiores.

$\mathrm{Y}$ no debe ser asf.

Las finalidades de una y otra enseñanza son totalmente diferentes y diferentes han de ser tambièn su trayecloria y sus medios. El programa secundario en vez de tender a hacer del niño, en cada ramo, un embrión de especialista, debería estar 
dirigido a capacitarlo para cualquiera de las actividades de la vida, a abrirle horizonles, a señalarle rumbos, a despertarle ideales. Los que deseen especializarse en uno u otro ramo del saber tienen las escuelas superiores donde con verdadero provecho y profundidad aprenderán las disciplinas a que su natural los incline.

En esta confusión de los fines de ambas enseñanzas está, a nuestro ver. el error fundamental de la educación secundaria en Chile: hay que dejar la erudición para los eruditos e ir. en humanidades, a la esencia. al espiritu de las cosas. Engendrar ideas en las mentes infantiles. despertar su inteligencia, será un trabajo a la par fecundo y grato para el niño; en cambio, rellenar su cerebro con mil y mil datos-dalos que se olvidan pronto y que habrá siempre que consultar en los libros-nunca podrá ser, por más que se alteren - transpongan las materias, sino una tarea fatigosa y estéril. 